\title{
A INSERÇÃO DA TEMÁTICA DE SUSTENTABILIDADE NA FORMAÇÃO DE FUTUROS GESTORES: COMO OS PROFESSORES SE DEPARAM COM O ASSUNTO?
}

\author{
THE INTEGRATION OF SUSTAINABILITY \\ IN MANAGEMENT EDUCATION: \\ HOW DO TEACHERS SEE THE SUBJECT?
}

Recebido em: 18/03/2015 A Aprovado em: 26/05/2015 Avaliado pelo sistema double blind review Editora Científica: Manolita Correia Lima DOI 10.13058/raep.2015.v16n3.284

\section{IZABELA TEIXEIRA FRANCO izaa.franco@hotmail.com MAÍSA GOMIDE TEIXEIRA \\ DENISE BARROS DE AZEVEDO \\ ROSAMARIA COX MOURA-LEITE \\ UNIVERSIDADE FEDERAL DE MATO GROSSO DO SUL}

\begin{abstract}
RESUMO
A integração da temática de sustentabilidade nos conteúdos educativos promove a formação de cidadãos responsáveis por suas ações e com consciência do seu papel na sociedade. Ao ser levado para as salas de aula, esse assunto assume relevância também para formação de administradores, que influenciarão direta ou indiretamente a tomada de decisão dentro das organizações que, por sua vez, são responsáveis pelo desenvolvimento das nações e por grande parte dos problemas os quais a proposta de sustentabilidade combate. O presente estudo de cunho qualitativo possui o objetivo de investigar como ocorre a inserção do tema dentro dos cursos de ensino superior em Administração. Este propósito é abarcado por meio de pesquisa bibliográfica, análise documental e pesquisa de campo, com enfoque no papel representado pelos docentes na veiculação do conteúdo sobre a sustentabilidade por meio das atividades acadêmicas. Verificou-se que os docentes consideram a sustentabilidade relevante para a formação dos futuros gestores, porém há divergência de opiniões quanto a sua abrangência.
\end{abstract}

Palavras-chave: sustentabilidade; educação para sustentabilidade; Administração.

\begin{abstract}
The integration of sustainability into educational content promotes the formation of citizens responsible for their actions and aware of their role in society. When introduced into the classroom, this subject is also relevant to management students who will directly or indirectly influence organizations' decision makers who, in turn, are responsible for the development of nations and for many of the problems sustainability theories are trying to solve. This qualitative study has the objective of investigating how this subject is integrated in higher education business courses. Bibliographic review, document analysis and field research are employed, focusing on the role played by teachers in the dissemination of content on sustainability through academic activities. It was found that teachers considered sustainability relevant to the training of future managers and business majors, but there are differing views on its scope. Keywords: sustainability; sustainability education; management.
\end{abstract}




\section{INTRODUÇÃO}

A busca pelo desenvolvimento das nações possibilitou o processo de industrialização e objetivou, em especial, o desenvolvimento econômico, gerando problemas relacionados à exploração maciça de recursos ambientais e sociais. Intensificaram-se, então, os questionamentos da sociedade quanto ao modelo de crescimento vigente, refletindo e buscando alternativas que conciliassem o desejo de desenvolvimento com a consciência de que isso deveria ocorrer respeitando limites socioambientais. Viver em harmonia com a natureza e uns com os outros é a essência da sustentabilidade (MEBRATU, 1998).

A palavra sustentabilidade é considerada abrangente por muitos autores, havendo confusões de terminologias ao se referir à mesma ideia. Porém, todos os termos afins empregados, buscam satisfazer de alguma forma o objetivo central da temática, que é unir questões sociais, ambientais e econômicas, buscando crescimento, porém sem comprometer gerações futuras.

Estudar a sustentabilidade com um olhar voltado para as organizações é muito importante, visto que as ações realizadas pelas empresas geram consequências para sociedade e o ambiente, tornando-as responsáveis por seus impactos. Porém, o interesse das empresas pelo tema ocorreu somente após pressão pública, havendo mudanças nas concepções existentes, onde práticas socioambientais eram feitas por caridade ou geravam apenas aumento de custos, e percebendo que também poderiam gerar oportunidades, inovação e vantagem competitiva. Assim, as empresas que visam apenas benefício próprio em detrimento da sociedade terão sucesso temporário e ilusório, visto que as organizações de sucesso carecem de uma sociedade saudável (PORTER; KRAMER, 2006).

Para Porter e Kramer (2006, p.I3) "a coisa mais importante que uma empresa pode fazer para a sociedade e para toda a comunidade é contribuir para uma economia próspera”. Os autores acreditam que por mais que pareça clichê, é verdade fundamental que empresa e sociedade precisam uma da outra e todas as ações realizadas pela primeira geram consequências sociais positivas ou negativas para a segunda. 
Dessa forma, é de grande valia a compreensão do quão importante é a formação universitária de bacharéis em administração que estejam conscientes de seu papel na sociedade, visto que poderão aplicar nas empresas os conceitos aprendidos em sala, guiando sua conduta e ações profissionais.

Quando se trata da abordagem da temática de sustentabilidade dentro dos cursos de Administração, alguns autores (GONÇALVES-DIAS; HERRERA; CRUZ, 2013; GOSHAL, 2005; JACOBI; RAUFFLET; ARRUDA, 20II; OLIVEIRA; SANT'ANNA; DINIZ, 20I4) concordam que a mesma ocorre ainda de maneira lenta, passando por uma mudança de pensamento, pois a visão tida até então era a de que os gestores deveriam objetivar o lucro organizacional a qualquer custo, não importando os meios para atingi-lo. Além disso, tem-se a ideia de que o tema deve ser abordado de maneira transversal, sendo trabalhado dentro de diversas disciplinas do curso (SILVA et al., 2013).

Com o propósito de ampliar o conhecimento sobre a temática, o presente estudo, de natureza qualitativa, buscou entender não apenas o conceito da sustentabilidade, como também a sua evolução histórica e relacionamento com a educação, sobretudo com o curso de graduação em Administração. Para isso, além de pesquisa bibliográfica visando análise da temática no cenário nacional e internacional, utilizou-se também a investigação documental e o estudo de caso, com entrevistas semiestruturadas a fim de compreender especificamente as opiniões de docentes sobre como ocorre o processo de conscientização dos discentes quanto à postura responsável que deverão assumir perante o mercado de trabalho.

O estudo se inicia com fundamentação teórica, que abrange a compreensão do relacionamento existente entre sustentabilidade e educação, seguida de um panorama sobre o ensino superior e o curso de Administração no Brasil, assim como o processo de abordagem transversal da temática de sustentabilidade nesses cursos. Posteriormente são apresentados os procedimentos metodológicos utilizados e os resultados obtidos por meio das análises das entrevistas realizadas com os docentes. 


\section{FUNDAMENTAÇÃO TEÓRICA}

\section{A CONSTRUÇÃO DE UM RELACIONAMENTO ESSENCIAL ENTRE SUSTENTABILIDADE E EDUCAÇÃO}

O poder e domínio do homem sobre a natureza e os animais permitiram que por muito tempo houvesse uma exploração ilimitada, a fim de satisfazer interesses sem se preocupar com os possíveis efeitos de suas ações, não havendo responsabilidade diante das consequências. Para Costa (2013, p. 190), dentro da problemática de responsabilidade vista nesse contexto "o discurso é sempre associado à predominância humana no mundo e ao suposto direito dos seres humanos de dominarem a natureza em seu favor; o grande problema vem da potencialidade de um desenvolvimento que não sustente a sobrevivência das gerações futuras".

De acordo com Redclift (1987) o termo sustentabilidade pode ter vários significados para diferentes pessoas. Para Cavalcanti (2003, p.I60) "sustentabilidade é a manutenção do sistema de suporte da vida que busca obedecer às leis da natureza buscando agir conforme uma perspectiva de longo prazo, obtendo contínuas condições de vida para um determinado grupo e para seus sucessores".

Em 1987 foi publicado um documento intitulado "Nosso Futuro Comum", elaborado pela Comissão Mundial sobre Meio Ambiente e Desenvolvimento, nomeada com o intuito de buscar soluções possíveis para os problemas ambientais decorrentes do desenvolvimento. Também conhecido como Relatório de Brundtland, tornou-se popular em todo o mundo, por ressaltar problemas vivenciados pela sociedade e propor a solução com base na difusão de um novo conceito: o desenvolvimento sustentável (MANITOBA EDUCATION AND TRAINING, 2000). O relatório define desenvolvimento sustentável como "o desenvolvimento que satisfaz as necessidades do presente sem comprometer a capacidade das gerações futuras satisfazerem as suas próprias necessidades". É importante salientar que o documento evidencia também, em vários momentos, o papel fundamental da educação para o desenvolvimento sustentável. 
Ao pesquisar sobre essa temática, são encontradas várias terminologias afins. Esses termos se misturam e muitas vezes podem se confundir, porém, ainda que cada um tenha sua peculiaridade, todos estão voltados para o aumento das reflexões e preocupação com a relação dos seres humanos entre si e para com o ambiente e como ela pode ocorrer de maneira coerente, sem que traga grandes prejuízos para os envolvidos.

Foi após a Revolução Industrial que esta relação de exploração entre sociedade e natureza começou a ficar insustentável, recebendo, assim, uma maior atenção e preocupação quanto aos rumos que a situação estava tomando. Todo o progresso e modernidade até então desejados pelas nações tiveram um preço e vieram acompanhados ta mbém do aquecimento global, da destruição do ozônio, perda de biodiversidade, erosão do solo, poluição do ar e da água, além de outros problemas que afetam a população humana, gerando impactos negativos principalmente para pessoas que sobrevivem e tiram seu sustento da terra (BANERJEE, 2003, p. I43-I80).

As discussões sobre a problemática ambiental mundial foram intensificadas após a década de 1970, tendo como marco a Conferência das Nações Unidas sobre o Meio Ambiente Humano realizada em 1972, em Estocolmo. Foi um dos eventos mais importantes relacionados a problemas ambientais desencadeados pelo desenvolvimento econômico desenfreado, propondo um desenvolvimento incorporado à preservação e manutenção do ambiente. Além de representar um grande avanço para a formação do conceito do desenvolvimento sustentável, já neste momento havia indícios de que as formas de busca de crescimento econômico teriam de ser alteradas (MEBRATU, 1998).

As nações participantes deste evento assinaram a Declaração da Conferência das Nações Unidas sobre Ambiente Humano, um documento com 26 princípios que discorre sobre o desenvolvimento sustentável, porém não acordaram quanto a sua implantação (MADEIRA, 2008).

Dentre os princípios estabelecidos, encontra-se o de número i9, que torna indispensável o "empenho para a educação em questões ambientais, dirigida tanto às gerações jovens como aos adultos e que preste a devida atenção ao setor da população menos privilegiado, para fundamentar as bases de 
uma opinião pública bem informada, e de uma conduta dos indivíduos, das empresas e das coletividades inspirada no sentido de sua responsabilidade sobre a proteção e melhoramento do meio ambiente em toda sua dimensão humana" (DECLARAÇÃO DA CONFERÊNCIA DAS NAÇÕES UNIDAS SOBRE O MEIO AMBIENTE HUMANO, 1972).

Também em 1972 houve a publicação de um novo documento feito por um movimento preocupado com a crise do meio ambiente, denominado Clube de Roma. O grupo composto por cientistas e cidadãos, criou um relatório que enfatizava sua preocupação com a expansão da crise ambiental, afirmando que a sociedade industrial estava ultrapassando os limites ecológicos ao promover o crescimento econômico até então empregado e que ambiente e desenvolvimento não poderiam permanecer em conflito por muito tempo (MEBRATU, 1998).

Ainda na década de 1970, houve um encontro em Belgrado, Iugoslávia, que resultou na criação de um documento que aponta como meta para a educação ambiental a formação de "uma população mundial consciente e preocupada com o meio ambiente e com os problemas associados, e que tenha conhecimento, aptidão, atitude, motivação e compromisso para trabalhar individual e coletivamente na busca de soluções para os problemas existentes e para prevenir novos". Objetivando a tomada de consciência sobre o assunto, deve-se buscar atingir o público em geral seguindo oito diretrizes básicas definidas no documento (MINISTÉRIO DO MEIO AMBIENTE, 20I4a).

Portanto, dentro desse contexto que envolve a sustentabilidade e o desenvolvimento sustentável, é possível perceber uma linha de amadurecimento das ideias e conceitos (considerando os pilares econômico, social e ambiental, definidos mais tarde por Elkington, 2004), que, em vários momentos, aponta para a educação como um instrumento fundamental para o alcance dos objetivos propostos.

Seguindo um histórico de acontecimentos relevantes, no âmbito nacional, foi sancionada em 198I a Lei $n^{\circ}$ 6.938, que estabeleceu a Política Nacional do Meio Ambiente, que tem por objetivo "a preservação, melhoria e recuperação da qualidade ambiental propícia à vida, visando assegurar, 
no país, condições ao desenvolvimento socioeconômico, aos interesses da segurança nacional e à proteção da dignidade da vida humana”. Tal lei tem como um de seus princípios a "educação ambiental a todos os níveis de ensino, inclusive a educação da comunidade, objetivando capacitá-la para participação ativa na defesa do meio ambiente”.

Novamente na década de 80 o país passou por debates relacionados à inserção da temática na educação, apontando para a necessidade de uma abordagem interdisciplinar. Em 1992, a cidade do Rio de Janeiro recebeu a Conferência das Nações Unidas sobre o Meio Ambiente e o Desenvolvimento, com a participação de I79 países, que assinaram um programa de ação denominado Agenda 2I, composto por 40 capítulos e objetivando desenvolvimento sustentável da sociedade (MINISTÉRIO DO MEIO AMBIENTE, 20I4b). Tamanha foi a importância deste evento, que acabou servindo de base para muitos outros, além de ter a reformulação e reafirmação dos compromissos políticos por meio da Rio+ıo, realizado em 2002 e o Rio+20, realizado em 2012.

No capítulo 36 da Agenda 2I, aborda-se a relevância da educação por meio de três áreas: reorientação do ensino no sentido do desenvolvimento sustentável; aumento da consciência pública e; promoção do treinamento. De acordo com o documento, tais áreas devem ser reconhecidas "como um processo pelo qual os seres humanos e as sociedades podem desenvolver plenamente suas potencialidades".

É ressaltado, ainda pela Agenda 2I, que para ser eficaz, o ensino voltado ao meio ambiente e desenvolvimento precisa "abordar a dinâmica do desenvolvimento do meio físico/biológico e do socioeconômico e do desenvolvimento humano (que pode incluir o espiritual), deve integrar-se em todas as disciplinas e empregar métodos formais e informais e meios efetivos de comunicação".

O papel da escola é fundamental na formação de pessoas integradas e integradoras do meio ambiente. Questões ambientais estão presentes em muitos discursos e documentos ultimamente, mas ainda estão distantes das ações diárias das escolas. Com a realização da Riog2 o tema foi muito expandido no Brasil, porém sete anos depois deste evento ainda 
se ensaiavam os primeiros passos na inserção da educação ambiental de maneira transversal nos currículos das escolas (LAMPERT, 1999).

Dessa forma, a educação entra como aliada na conscientização e transformação de cidadãos, fazendo com que percebam seu papel na sociedade para o alcance de um desenvolvimento sustentável. Com seu caráter transformador, a educação ambiental no Brasil passou a ter certo reconhecimento somente na década de 90, após a criação da Lei no 9.795/99 (RUSCHEINSKY, 2002).

A educação ambiental tornou-se obrigatória em todos os níveis de ensino com a lei $\mathrm{n}^{\circ}$ 9.795, sancionada em 1999, a qual se define em seu artigo primeiro como "... os processos por meio dos quais o indivíduo e a coletividade constroem valores sociais, conhecimentos, habilidades, atitudes e competências voltadas para a conservação do meio ambiente, de uso comum do povo, essencial à sadia qualidade de vida e sua sustentabilidade".

Já o ano de 1997 foi marcado pela Conferência Internacional em Ambiente e Sociedade: Educação e Conscientização Pública para a Sustentabilidade, realizada em Tessaloniki, Grécia, com mais de 83 nações representadas. (MINISTÉRIO DO MEIO AMBIENTE, 20I4C). Dentre as conclusões do documento resultante dessa conferência, é ressaltada novamente a importância da educação para o meio ambiente e a sustentabilidade, devendo ser tratada de forma interdisciplinar, com planos de ação em nível local e regional. Além do mais, o fortalecimento dos programas de formação de docentes é frisado neste documento como essencial no processo de reversão da crise ambiental e social (BARBIERI; SILVA, 20II).

Somente nos anos 2000 as abordagens sobre aspectos ambientais e sociais começaram a ser debatidas com mais intensidade em empresas, universidades e na sociedade como um todo. Essa preocupação se deu pela emergência de ações para combater problemas causados pelas ações humanas, que assumiram uma proporção muito grande, a ponto de se temer não conseguir mais detê-los ou fazê-los regredir (COSTA, 2013).

Com toda a problemática ambiental e social em evidência, em dezembro de 2002, a Assembleia Geral das Nações Unidas, por meio da Resolução $n^{\circ}$ 57/254, instituiu o período entre 2005 e 2014 como Década da Educação das 
Nações Unidas para o Desenvolvimento Sustentável, elegendo a UNESCO para liderar e implantar esse projeto (UNESCO, 2005). No documento elaborado, a educação entra como aliada do processo de desenvolvimento sustentável, possibilitando a formação de valores, atitudes, capacidades e comportamentos dos indivíduos para que possam construir uma sociedade sustentável e mais justa.

De acordo com o plano organizado pela UNESCO, a educação para o desenvolvimento sustentável deve ser abordada de maneira interdisciplinar e holística (integrando todas as disciplinas do currículo), com multiplicidade de métodos e permitindo que o aluno possa associar as teorias e conteúdos às ações práticas da vida pessoal e profissional, adquirindo visão local e global dos problemas nas dimensões sociais, ambientais e econômicas. Para esse aluno, deve-se visar à aquisição de valores de cidadania e a formação de senso crítico, assim como o desenvolvimento de sua capacidade de resolução de problemas e tomada de decisões.

Com base no que se discorreu acima, é possível perceber que com o passar do tempo e o amadurecimento de ideias e propostas relacionadas à sustentabilidade e ao desenvolvimento sustentável, a temática passou a ser concebida de maneira cada vez mais interligada com a educação.

\section{O ENSINO SUPERIOR E A FORMAÇÃO DO ADMINISTRADOR NO}

\section{BRASIL}

O papel das instituições de Ensino Superior vai além de educar futuras gerações na tomada de decisão, sendo relevantes também para um futuro global mais sustentável. A preocupação com a abordagem da temática da sustentabilidade nas instituições de ensino vem crescendo e vários países a estão integrando aos planos de educação, ainda que haja muitos conflitos quanto à ambiguidade e diversidade do seu conceito e aprendizagem (JACOBI; RAUFFLET; ARRUDA, 20II).

A Lei de Diretrizes e Bases da Educação Nacional, no 9.394, sancionada em 20 de dezembro de 1996 afirma em seu artigo primeiro que "a educação abrange os processos formativos que se desenvolvem na vida familiar, na convivência humana, no trabalho, nas instituições de ensino e pesquisa, nos 
movimentos sociais e organizações da sociedade civil e nas manifestações culturais".

Ainda de acordo com essa lei, o Ensino Superior possui sete finalidades básicas, dentre elas o estímulo à criação cultural e ao pensamento reflexivo; a formação de diplomados aptos ao mercado de trabalho; incentivo à pesquisa e investigação científica; promover a divulgação de conhecimentos e comunicar o saber; suscitar o desejo permanente de aperfeiçoamento profissional e cultural; estimular o conhecimento de problemas regionais, nacionais e do mundo, prestando serviços à comunidade e estabelecendo uma relação de reciprocidade.

De acordo com dados divulgados pelo Censo 2012, o Brasil possuía, até então, um total de 2.416 instituições de Ensino Superior, sendo 154 na região Norte, 444 na região Nordeste, II73 na região Sudeste, 409 na região Sul e 236 na região Centro-Oeste. Nestas, são oferecidos 31.866 cursos distintos, divididos entre licenciatura, bacharelado e tecnólogo.

Ao todo são cerca de 7.037.688 matrículas, com um total de 5.923.838 compondo o ensino presencial e I.II3.850 no ensino a distância. Deste total, I.325.374 estão frequentando algum curso na área de Gerenciamento e Administração, o que significa que cerca de $19 \%$ dos alunos matriculados no nível superior no Brasil receberão formação para atuar como gestores futuramente no mercado de trabalho. Tais dados reforçam a importância de se ter o devido cuidado e estima com o ensino da temática de sustentabilidade em sala de aula, visto que quase $20 \%$ dos profissionais formados (considerando o quadro atual de ingressos) trabalharão com a gestão, influenciando direta ou indiretamente as tomadas de decisões nas organizações.

O Conselho Nacional de Educação, por meio da Resolução ${ }^{\circ} 4$, de 13 de julho de 2005 institui as Diretrizes Curriculares Nacionais do Curso de Graduação em Administração, que devem ser seguidas por todas as instituições de Ensino Superior. De acordo com o artigo terceiro da lei, o perfil almejado para o formando dessa área inclui "capacitação e aptidão para compreender as questões científicas, técnicas, sociais e econômicas da produção e de seu gerenciamento, observados níveis graduais do 
processo de tomada de decisão, bem como para desenvolver gerenciamento qualitativo e adequado, revelando a assimilação de novas informações e apresentando flexibilidade intelectual e adaptabilidade contextualizada no trato de situações diversas, presentes ou emergentes, nos vários segmentos do campo de atuação do administrador".

\section{A TRANSVERSALIDADE DA TEMÁTICA SUSTENTABILIDADE NA FORMAÇÃO DO ADMINISTRADOR}

A responsabilidade com questões ambientais e sociais pode trazer benefícios para as empresas que saibam agir conforme seus preceitos, possibilitando a criação de vantagem competitiva. Porter e $\operatorname{Kramer}(2006$, p.2) acreditam que se as empresas soubessem valorizar mais essa responsabilidade "elas descobririam que a RSE pode ser muito mais do que um custo, uma restrição, ou um ato de caridade - ela pode ser uma fonte de oportunidade, inovação e vantagem competitiva”.

A visão cartesiana, até então utilizada pelo mundo dos negócios, fragmentada e justificada por relações de causa e efeito, passa a dar lugar a um olhar holístico, mais complexo e integrador, com interação e relacionamento de todos que compõem o ambiente de negócios sustentáveis (VASCONCELOS; SILVA JUNIOR; SILVA et al., 20I3). Porém, no que diz respeito à abordagem desses assuntos em termos acadêmicos, na formação de profissionais conscientes, ainda existem muitas lacunas que devem ser preenchidas (COSTA, 2013).

Para Aktouf (2005) as escolas de gestão são conservadoras e formam profissionais que tendem a reproduzir modelos já formulados e testados, onde o capital é o principal fator de interesse, divergindo dos interesses relacionados ao fator humano e meio ambiente. Ainda segundo esse autor, para que houvesse uma transformação no ensino da Administração, com profissionais que visassem uma lógica de mudança, seria necessária a reforma de algumas características, dentre elas a "definição restrita de administração centrada na predominância do fator capital e na preocupação do enriquecimento individual" (AKTOUF 2005, p.I52).

De acordo com Jacobi, Raufflet e Arruda (20II) as ações educativas com enfoque para sustentabilidade visam à formação de sujeitos críticos, 
tornando-os capazes de mudanças de comportamentos e atitudes, conscientes do seu papel coletivo. Com relação a isso, os autores acreditam que:

Essa mudança paradigmática implica uma mudança de percepção e de valores, gerando um pensamento complexo, aberto às indeterminações, às mudanças, à diversidade, à possibilidade de construir e reconstruir, em um processo contínuo de novas leituras e interpretações, configurando novas possibilidades de ação (JACOBI; RAUFFLET; ARRUDA, 20II, p.28).

Nos cursos de Administração a adequação dos currículos aos princípios da educação para sustentabilidade ocorreu de maneira mais lenta, sofrendo até mesmo certa resistência, visto que os gestores tinham receio de que essa nova abordagem trouxesse aumento nos custos (TEODÓSIO et al., 2005). Corroborando com esta afirmação, Sinay et al. (2013) ressaltam que "a área de administração ficou um tanto alheia a esse movimento, talvez pela dificuldade de gestores perceberem que negócios verdes podem ser lucrativos".

Baseando-se em contexto evolutivo, na maioria das vezes, uma necessidade prática ou demanda externa (advinda das empresas) possibilita a criação e adesão de novas teorias no curso de Administração. Contudo, em relação à sustentabilidade, ainda que as teorias estejam voltadas para questões econômicas, sociais e ambientais, a abordagem da temática no curso é deficiente, sendo ensinada como uma obrigação moral e legal. Na prática, a responsabilidade social das empresas ainda se mostra reativa, agindo conforme exigências das leis e cobranças da sociedade, assim como busca atuar de maneira que possa transmitir uma imagem e reputação responsáveis (JACOBI; RAUFFLET; ARRUDA, 20II).

Os objetivos da administração de uma organização vão além dos limites da mesma, portanto o administrador é um agente de mudança muito importante para sociedade (VENZKE; NASCIMENTO, 20I3). Esse pensamento alinha-se com as ideias de Palma, Oliveira e Viacava (20II), que consideram que para preparar bons gestores, com consciência, poder de decisão e reflexão, agentes em busca da sustentabilidade, os cursos na área de Administração precisam ser tratados de maneira mais ampla, visando 
não apenas aspectos econômicos, como também os ambientais e sociais, devendo adequar seus currículos aos avanços da sociedade.

Uma possibilidade para a abordagem da sustentabilidade nos cursos de Administração é o seu tratamento transversal dentro das instituições de ensino, o qual é definido por Barbieri e Silva (20II, p.150) como "um conjunto de temas que devem ser integrados nas diversas disciplinas oferecidas pelo curso". Eles afirmam ainda que a ideia é "fazer a preocupação ambiental penetrar por capilaridade nas disciplinas das matérias básicas, instrumentais e de formação profissional, para que o futuro administrador inclua o meio ambiente e a sociedade em todas as suas decisões".

Portanto, a educação é uma instância mediadora onde se possibilita a relação mútua entre indivíduo e sociedade, tendo como um dos seus atuais desafios à inserção de uma abordagem holística que supere a fragmentação das disciplinas, com professores que saibam lidar com os conteúdos dessa forma e não como compartimentos estanques (ARANHA, 1996).

A transversalidade, assim como a interdisciplinaridade vão contra uma análise de dados estanques como representantes da realidade, considerando a complexidade do mundo atual e tendo como objetivo o envolvimento entre as disciplinas, não devendo tratar determinado assunto isoladamente em apenas uma disciplina, como é o caso da sustentabilidade em diversos cursos de administração brasileiros (SILVA et al., 2013).

A problemática dos projetos pedagógicos das instituições de ensino está relacionada à falta de articulação entre as disciplinas e ao distanciamento do que é ensinado em relação à realidade dos alunos (DEMAJOROVIC; SILVA, 20I2). O educador possui papel decisivo e estratégico na formação de alunos críticos e conscientes da crise socioambiental e da necessidade de transformação para uma cidadania ambiental (JACOBI; RAUFFLET; ARRUDA, 20II). O tratamento transversal da temática ambiental só será capaz se houverem profissionais que conheçam o mesmo em nível elevado, indo além dos conhecimentos específicos das disciplinas ministradas (BARBIERI; SILVA, 20II).

A implantação do tema sustentabilidade no curso de administração passa por alguns desafios e riscos, exigindo novos modelos de ensino- 
aprendizagem, que ampliem capacidades ao nível não apenas do ensino, como também da investigação e das relações com a sociedade. Assim, as universidades têm papel de suma importância nesse quesito, pois podem colaborar para a geração de cultura voltada para práticas, atitudes e comportamentos positivos em relação à sustentabilidade (GONÇALVESDIAS; HERRERA; CRUZ, 20I3). 


\section{PROCEDIMENTOS METODOLÓGICOS}

O presente estudo de cunho qualitativo possui o objetivo de investigar como ocorre a inserção da temática de sustentabilidade dentro dos cursos de ensino superior em Administração. Este propósito é abarcado por meio de um estudo de caso no curso de graduação em Administração da Universidade Federal do Mato Grosso do Sul, campus de Campo Grande, que tem como enfoque a compreensão do papel representado pelos docentes na veiculação de conteúdos, relacionados ao tema, por meio das atividades acadêmicas.

A pesquisa, de acordo com Vergara (2005), é caracterizada como descritiva, com o intuito de conhecer, explicitar e contextualizar o tema dentro da instituição de ensino em questão, assim como relatar a realidade de um elemento e esclarecer fatores que contribuem para a ocorrência de determinado acontecimento.

Antes da pesquisa de campo foi realizado um levantamento bibliográfico visando trabalhos anteriores que abordaram a evolução do conceito de sustentabilidade para sociedade, sua associação com a educação, assim como a abordagem empírica em cursos de Administração. Além disso, a análise documental precedeu a pesquisa de campo.

A análise documental ocorreu por meio de materiais disponibilizados em sítios eletrônicos oficiais de universidades brasileiras e envolveu duas etapas. A primeira abrangeu a análise da ementa curricular do curso de Administração nas dez melhores instituições do país, eleitas segundo o Ranking Universitário elaborado pela Folha de São Paulo em 20I4. As universidades eleitas foram: UFRJ, UFRGS, UFMG, USP, FGV-EAESP, EBAPE, PUC-SP, UFBA, UFPR e Mackenzie, todas com notas entre quatro e cinco pelo ENADE - Exame Nacional de Desempenho de Estudantes. Foram avaliadas universidades com base em duas grandes áreas: avaliação do mercado e qualidade do ensino (fundamentada na formação e dedicação dos docentes, nota no ENADE e avaliação realizada por 6II professores escolhidos pelo MEC). De acordo com esse ranking o curso de Administração da UFMS está posicionado em $67^{\circ}$ lugar. 
Após essa primeira etapa foi possível perceber de que forma a temática da sustentabilidade vem sendo tratada formalmente nos cursos de Administração brasileiros bem conceituados. Considerando os conteúdos programáticos disponibilizados nos sítios eletrônicos das universidades, foi possível identificar temas formais que direta ou indiretamente relacionamse com a sustentabilidade em seu enfoque organizacional.

Dentre as similaridades verificadas, percebeu-se que seis universidades (UFRGS, UFMG, UFBA, EBAPE, PUC-SP e Mackenzie) possuem pelo menos uma disciplina obrigatória voltada especificamente para temática da sustentabilidade, gestão socioambiental e responsabilidade social das empresas, enquanto outras disciplinas contam com assuntos que relacionam seu tema central com questões sustentáveis, tais quais: Visão Sistêmica das Organizações; Estrutura e Análise de Mercados; Economia Brasileira; Estudos Sociopolíticos e Ambientais; Administração do Terceiro Setor; Tópicos Especiais de Marketing; Consumo Consciente e Logística Reversa; Desafios brasileiros para a Sustentabilidade; Governança Corporativa; Filosofia e; Gestão Estratégica.

Quanto às disciplinas eletivas, nem todas as instituições disponibilizam um ementário descritivo (PUC-SP, EBAPE e FGV - EAESP), visto que há maior flexibilidade na abordagem de conteúdos por parte do docente que ministrará as aulas em cada semestre. Porém, alguns assuntos relacionados ao tema podem ser verificados dentro de disciplinas que foram especificadas, tais como: Administração estratégica de projetos; Marketing Social; Administração e Meio Ambiente; Empreendedorismo Social e; Consumo Consciente nas Organizações. Além disso, oito instituições têm a preocupação em inserir a ética como conteúdo imprescindível e valioso para a formação do administrador, tanto com enfoque filosófico, quanto social e organizacional.

Este conjunto de dados serviu de estimativa para a segunda etapa de análise documental, que tratou da apreciação da ementa curricular do curso de Administração da UFMS, assim como a realização de análises comparativas, checando quais os temas abordados por estas instituições que também estão presentes nas disciplinas ministradas dentro do curso 
na UFMS. Para isso, uma tabela com assuntos que podem contribuir para a formação de administradores socialmente responsáveis, tais como: Ética e moral; Compromisso da empresa com a sociedade; Importância do meio ambiente e sua preservação; Cultura, direitos e deveres; Consumo e seus efeitos; Sustentabilidade, conceitos, aplicabilidade; Responsabilidade Social Corporativa; Leis e políticas públicas; Mercado Verde; Tecnologia e Inovação; Valores e atitudes; Processo de tomada de decisão; Empreendedorismo sustentável; Imagem/Reputação corporativa; Discussões reflexivas que estimulam o senso crítico.

A revisão da literatura e as análises documentais serviram também de subsídio para a etapa seguinte do estudo, a pesquisa de campo, fornecendo conteúdo para a elaboração de um roteiro semiestruturado de entrevista, aplicado individualmente com II docentes dentre os 20 que ministraram alguma disciplina durante o ano letivo de 20I4 no curso de Administração da UFMS. Isto estaria condizente com Richardson et al. (1999) quando diz que a melhor forma de compreender e participar da mente do outro é a interação face a face, sendo este um elemento fundamental das pesquisas em Ciências Sociais, que permite o estreitamento de relações (RICHARDSON et al., I999). Os entrevistados são identificados nos resultados da pesquisa por letras que seguem a ordem alfabética, de A a K.

Com o intuito de absorver opiniões relacionadas à abrangência formal do tema (políticas, exigências e ações por parte da instituição) e à abordagem informal (ações e atitudes por parte dos docentes nas aulas), foram elaboradas quatorze propostas de questionamentos que conduziram as conversas. Tais propostas foram divididas com base em três expectativas de coleta de dados: (i) identificar a formação, tempo de atuação, projetos desenvolvidos pelo entrevistado e alinhamento das disciplinas com a temática; (ii) conhecer a opinião do entrevistado com relação ao tema e o grau de importância atribuído ao mesmo; (iii) compreender o envolvimento prático dos professores entrevistados com a sustentabilidade no contexto de sala de aula e as ações realizadas no sentido de promover comportamentos sustentáveis.

Do total de questões do roteiro, doze eram dissertativas, uma questão era objetiva e uma questão utilizava a tabela com os quinze temas selecionados 
anteriormente, prováveis de se relacionar com o enfoque sustentável. A Tabela 2 foi criada baseada na análise das ementas curriculares pertencentes aos dez melhores cursos de administração do Brasil. Foram observados os assuntos contidos nos programas de disciplinas que podem contribuir para a formação de administradores conscientes de seu papel na sociedade e das possíveis consequências de suas ações. Para mensurar o grau de envolvimento dos docentes com estas questões em sala de aula, utilizou-se a escala Likert (de zero a cinco) na qual, ao assinalar o número zero, o docente alegava não tratar do assunto em suas aulas e ao assinalar o número cinco, indicava que o item está inteiramente ligado ao conteúdo das disciplinas. 


\section{RESULTADOS E ANÁLISES}

A análise dos resultados a seguir está dividida em duas fases. A priori, realizou-se uma análise documental da UFMS, assim como uma apreciação comparativa das grades curriculares entre os melhores cursos de Administração do Brasil e a UFMS, no intuito de verificar se a abrangência do tema está seguindo os padrões das demais. Em seguida, será feita a análise das entrevistas realizadas com os docentes, visando compreender percepções e atitudes relacionadas ao tema.

\section{O CURSO DE ADMINISTRAÇÃO DA UFMS - OBSERVAÇÃO}

\section{CURRICULAR}

O curso de Administração da UFMS, campus de Campo Grande, oferta um total de 47 disciplinas, totalizando uma carga horária de 3.000 horas, incluindo as atividades complementares (com carga horária de 348 horas). As disciplinas da grade se dividem entre 32 obrigatórias (com carga horária de 2.040 horas) e 15 optativas (com carga horária de 6I2 horas), as quais são denominadas Tópicos Especiais Interdisciplinares e permitem aos alunos que escolham as áreas nas quais possuem maior interesse e desejam se aprofundar.

Ao se deparar com a ementa curricular do curso, verifica-se que nenhuma disciplina obrigatória apresenta a temática de sustentabilidade como objeto central de estudo, contendo apenas alguns assuntos que podem ser relacionados ao tema dentro das disciplinas. Optou-se, então, por realizar um comparativo dos temas evidenciados pela análise das ementas curriculares dos cursos de Administração das dez instituições de ensino superior (IES) eleitas ( ${ }^{\mathrm{a}}$ etapa) e também da UFMS. A Tabela I apresenta os temas abordados pelas instituições e se o tema foi abordado na UFMS. 
Tabela I Temas abordados formalmente nas IES

\begin{tabular}{|c|c|c|}
\hline Tema & $\begin{array}{l}\text { Instituições que abordam o tema } \\
\text { formalmente }\end{array}$ & $\begin{array}{l}\text { O tema foi abordado } \\
\text { formalmente na UFMS? }\end{array}$ \\
\hline Ética e moral & $\begin{array}{l}\text { UFRJ; UFRGS; USP; EAESP; EBAPE; PUC- } \\
\text { SP; UFBA; UFPR; Mackenzie }\end{array}$ & Sim \\
\hline $\begin{array}{l}\text { Compromisso da empresa com a } \\
\text { sociedade }\end{array}$ & UFRJ; UFRGS; UFMG; USP; EBAPE; UFBA & Sim \\
\hline $\begin{array}{l}\text { Importância do meio ambiente e } \\
\text { sua preservação }\end{array}$ & UFRJ; UFRGS; UFMG; EBAPE; UFBA & Não \\
\hline Cultura, direitos e deveres & $\begin{array}{l}\text { UFRJ; UFRGS; UFMG; USP; EBAPE; } \\
\text { UFBA; UFPR; Mackenzie }\end{array}$ & Sim \\
\hline Consumo e seus efeitos & $\begin{array}{l}\text { UFRGS; UFMG; USP; EBAPE; UFBA; } \\
\text { UFPR; Mackenzie }\end{array}$ & Sim \\
\hline $\begin{array}{l}\text { Sustentabilidade, conceitos, } \\
\text { aplicabilidade }\end{array}$ & USP; EBAPE; PUC-SP; UFBA; Mackenzie & Não \\
\hline $\begin{array}{l}\text { Responsabilidade Social } \\
\text { Corporativa }\end{array}$ & $\begin{array}{l}\text { UFRJ; UFMG;USP; EBAPE; UFBA; } \\
\text { Mackenzie }\end{array}$ & Não \\
\hline Leis e políticas públicas & $\begin{array}{l}\text { UFRJ; UFRGS; UFMG; USP; EAESP; } \\
\text { EBAPE; PUC-SP; UFBA; Mackenzie }\end{array}$ & Sim \\
\hline Mercado Verde & EBAPE; & Sim \\
\hline Tecnologia e Inovação & $\begin{array}{l}\text { UFRJ; UFRGS; UFMG; USP; EBAPE; PUC- } \\
\text { SP; UFBA; Mackenzie }\end{array}$ & Sim \\
\hline Valores e atitudes & $\begin{array}{l}\text { UFRJ; UFRGS; USP; EBAPE; UFPR; } \\
\text { Mackenzie }\end{array}$ & Sim \\
\hline Processo de tomada de decisão & $\begin{array}{l}\text { UFRJ; UFMG;USP; EAESP; EBAPE; PUC- } \\
\text { SP; UFBA; UFPR; Mackenzie }\end{array}$ & Sim \\
\hline Empreendedorismo sustentável & UFMG; USP; Mackenzie & Não \\
\hline Imagem/Reputação corporativa & UFMG; UFPR & Sim \\
\hline $\begin{array}{l}\text { Discussões reflexivas que } \\
\text { estimulam o senso crítico }\end{array}$ & $\begin{array}{l}\text { UFRJ; UFRGS; UFMG; USP; EAESP; } \\
\text { EBAPE; PUC-SP; UFBA; UFPR; Mackenzie }\end{array}$ & Sim \\
\hline
\end{tabular}

Com base nos dados da Tabela I, é possível verificar que a UFMS não aborda formalmente e conceitualmente quatro temas dentro de suas disciplinas obrigatórias. São eles: Importância do meio ambiente e sua preservação; Sustentabilidade, conceitos, aplicabilidade; Responsabilidade Social Corporativa e; Empreendedorismo Sustentável. Porém alguns dos temas são abordados dentro de sete delas, colaborando direta ou indiretamente para a conscientização dentrodaárea. Sãoeles:inovação e tecnologia(Administração 
de Produção e Operações); consumo e comportamento do consumidor (Administração Mercadológica e Microeconomia); responsabilidade social e ética nos negócios (Administração Mercadológica); valores e atitudes (Comportamento Organizacional); ética e filosofia como saber reflexivo e crítico (Introdução à Filosofia) e; direito ambiental (Introdução ao Direito). Além disso, a leitura do ementário proporcionou a visão de outros dois temas que contribuem no processo de conscientização dos futuros gestores, são eles: viabilidade econômica de projetos (Elaboração e Avaliação de Projetos) e; novas demandas ambientais para o gestor (Introdução à Administração).

Outra análise é possível ser feita ao observar a Figura I, apresenta a quantidade de temas abordados formalmente por cada instituição pesquisada. É possível verificar que a instituição EBAPE aborda um número maior de assuntos que contribuem para o conhecimento da temática de sustentabilidade, incluindo no currículo treze dos quinze temas. Em segundo lugar está posicionada a USP, com doze temas, seguida pela UFMG, UFBA e Mackenzie. A figura também nos permite perceber que, a instituição FVG-EAESP é a que aborda formalmente a menor quantidade de temas, seguida pela PUC-SP, o que poderia sugerir que essas instituições abordam esses conteúdos em disciplinas eletivas ou que por mais que essas instituições se enquadrem dentre as melhores do país, o curso ainda não está totalmente alinhado a tendência de unir o ensinamento da administração às questões sociais, ambientais e econômicas.

Ao comparar essas instituições com a UFMS, é possível perceber que por mais que esteja atrás das demais, de acordo com o ranking apresentado pela Folha de São Paulo, a universidade aborda onze dos quinze temas abordados formalmente pela IES, assim como UFMG, UFBA e Mackenzie. 
Figura I Temas abordados formalmente pelas IES

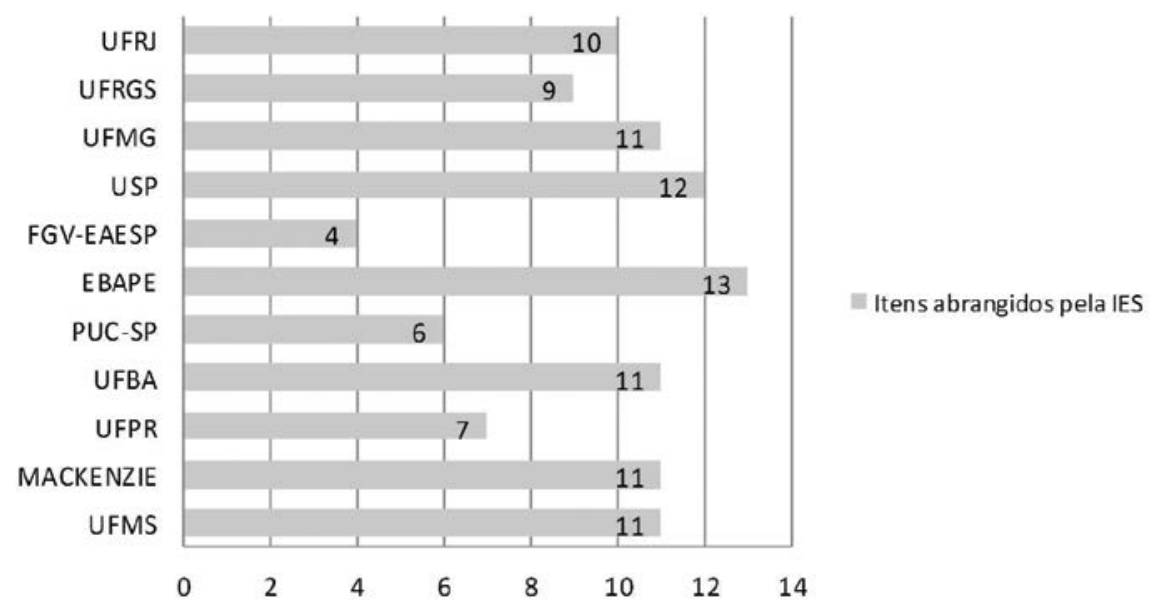

Em relação às ementas das disciplinas eletivas, que na UFMS são denominadas Tópicos Especiais Interdisciplinares, não foi possível obter informações por meio dos dados coletados, pois constam na ementa como "estudos sobre fatos e fenômenos ligados à área de Administração", visando o enriquecimento da formação pessoal, profissional e científica do aluno, porém sem explicitar o conteúdo abordado.

Após a apreciação documental do ementário, foi possível compreender como ocorre a abordagem formal do tema na UFMS, porém percebeu-se que tais informações podem se mostrar vagas e genéricas, visto que os assuntos são apenas citados dentro das grades das disciplinas, sem aprofundamento a respeito da maneira como são trabalhados em sala de aula. Dessa forma, constatou-se a necessidade de captar dados mais específicos por meio de entrevistas com docentes, a fim de saber mais detalhes sobre o processo prático de ensino e aprendizagem na instituição, bem como conhecer de que forma esses professores trabalham dentro das disciplinas eletivas, que não tiveram seus conteúdos disponibilizados no documento. 


\section{ABORDAGEM DA TEMÁTICA PELA VISÃO DOS DOCENTES}

Buscando informações mais aprofundadas e específicas, foram contatados os vinte professores que compuseram o quadro do curso no ano de 20I4, a fim de agendar entrevistas para conhecer suas práticas, valores e opiniões. Deste total foram entrevistados onze docentes.

Atendendo à expectativa $i$ de coleta de dados, identificou-se que dos onze entrevistados, sete são graduados em Administração e quatro se dividem entre Geografia, Ciências Econômicas, Agronomia e Matemática. Ao todo, são responsáveis por dezoito disciplinas do quadro do curso no ano de 20I4, sendo doze obrigatórias e seis optativas. Dois dos docentes estão dando aulas para o curso num período equivalente ou menor que seis meses, quatro deles entre dois e três anos e cinco estão no curso de administração num período que varia de cinco a quinze anos. Tais dados permitem compreender o quão multidisciplinar é o curso, podendo contar com o conhecimento de profissionais formados em várias áreas, bem como permite analisar as divergências ou similaridades nas respostas de pessoas que estão vinculadas há pouco tempo no curso e pessoas que estão há mais de uma década contribuindo para formação de administradores na cidade.

Além dos conteúdos previstos formalmente no ementário, a maioria dos professores afirma que alinha conteúdos à temática de sustentabilidade tanto dentro das disciplinas optativas, quanto informalmente nas obrigatórias, abordando questões como a sustentabilidade financeira, produção limpa, ética digital, agricultura orgânicas, técnicas sociais de produção e tendências do mundo dos negócios. Para o docente $\mathrm{B}$, atualmente todos os docentes acabam passando informalmente por esse tema nas suas disciplinas. Ele afirma que em sua disciplina "por exemplo, a gente a todo o momento evita a utilização de papel, e explica a necessidade de utilizar o sistema de uma forma correta, para poder evitar desperdício de materiais que não são necessários mais hoje em dia”.

$O$ respondente I afirma que além das abordagens informais do tema, também já trabalhou anteriormente com disciplinas optativas que tiveram a sustentabilidade como enfoque, tais como: Tópicos Especiais 
em Responsabilidade Social das Organizações em 2012 e 2013 e Seminário temático em Responsabilidade Social Corporativa em 201 e 2012.

Fora da grade do curso, três docentes afirmaram que não estão trabalhando com nenhuma atividade extracurricular no momento e os demais possuem projetos de pesquisa e extensão em diversas áreas. Quatro dos projetos em vigência possuem alguma relação direta ou indireta com a temática da sustentabilidade e do desenvolvimento sustentável. Além disso, três professores já realizaram projetos anteriores na área, sendo uma das linhas de pesquisa adotadas por dois destes, por considerarem ser um tema relevante para a área de Administração. Ainda de acordo com o entrevistado $\mathrm{A}$, vale ressaltar que antigamente a sustentabilidade era vista de outra forma, o que refletia nos projetos acadêmicos desenvolvidos.

Antigamente desenvolvimento sustentável era análise de viabilidade econômica. O empreendimento dá retorno? Gera recursos? Muito lucro? Pouco lucro? Então era essa que era nossa sustentabilidade. Hoje você agrega além do lucro, se você está dando o ganho social. Normalmente as empresas não estão muito preocupadas com esse ganho social. Claro que se faz muito marketing a respeito disso, mas no fundo vai pesar sempre a parte econômica, se a parte social não der lucro ou der muito prejuízo, deixa de lado (Informação verbal).

Visando atender as expectativas ii e iii de coleta de dados, foi questionado se os docentes consideram que existe interesse por parte da UFMS em promover a conscientização dos discentes para uma orientação sustentável. Três deles foram enfáticos em dizer que sim, enquanto os demais discordaram dando justificativa de que não há muitas ações práticas, e que se existem ações com esse teor elas não são divulgadas e fomentadas. Ainda de acordo com o professor $\mathrm{H}$ "não há nenhum trabalho nesse sentido, mesmo porque a instituição não possui uma política para a área”. Contrário à opinião anterior, o respondente D expõe a seguinte justificativa:

Acredito que, até onde conheço, existe sim. A gente percebe isso no curso pelas ementas das disciplinas, pela própria estrutura do curso. Então, existem algumas disciplinas direcionadas para esse tipo de discussão, que foram sendo incorporadas. Acho isso muito importante. Agora, fora isso, fora essa 
questão que a gente percebe no curso de Administração, onde tenho mais contato, eu não vejo ações da universidade sendo promovidas, pelo menos que tenham grande visibilidade. A gente não fica sabendo aqui. Pode estar ocorrendo sim, mas talvez o problema seja essa questão da visibilidade. Aliás, a minha hipótese é que esteja acontecendo e a gente não está sabendo (Informação verbal).

Todos os docentes concordaram com o fato de que a inserção da temática no curso afeta a atuação profissional dos futuros gestores. Para D "[...] cada vez mais o mercado de trabalho e a própria sociedade demandam a discussão dessas questões". Corroborando com essa ideia, o entrevistado $\mathrm{H}$ complementa que "sem essa sensibilização, os alunos não internalizarão a necessidade das organizações observarem o quanto a sustentabilidade pode afetar os negócios e a qualidade de vida dos seus colaboradores".

Ainda em relação à inserção da temática no curso, dois docentes fizeram uma ressalva, sugerindo que esse canal não é o único. $O$ entrevistado $G$ afirma que "colabora se onde o aluno mora, trabalha e estuda, tem sempre acesso a essas informações. Mas existem outros canais por aí a fora que têm trabalhado melhor isso e as próprias disciplinas trabalham numa forma mais formal", enquanto o entrevistado A complementa que "quando eles forem para o mercado de trabalho, vão ter que se adequar às políticas da empresa. Se ela tiver essa preocupação sustentável, eles vão ter que se ajustar a isso, ou, se a empresa não tiver, também não vão se preocupar muito".

As opiniões entram em conflito ao discutir se atualmente esses alunos saem preparados para assumir essa postura no mercado de trabalho. Enquanto a minoria considera que sim, os demais se dividem entre o preparo insuficiente e superficial (preso a conceitos), salientando que outros fatores contribuem para essa formação, como a participação em projetos de pesquisa e extensão, as exigências do mercado e o interesse do próprio aluno pelo tema.

[...] aqui na UFMS não está explícito isso, não está no discurso das pessoas, não está na preocupação. A Universidade por si só tem esse teor social, mas isso não está no dia a dia e não tenho dúvidas que reflete na atuação profissional dos alunos, porque se isso não for discutido em sala, o aluno não vai sair com essa consciência [...]. 
O discurso da UFMS, nesse curso de Administração, ainda é muito voltado para o desempenho da empresa enquanto empresa, da sobrevivência no ambiente competitivo, desempenho organizacional, lucratividade. Mas onde está essa empresa? Qual é o seu impacto em relação ao meio ambiente, às pessoas, aos próprios empregados? Parece que isso ainda não está muito vivo dentro das discussões acadêmicas. Às vezes as iniciativas que eu vejo partem dos próprios alunos [...] está incorporado nos valores individuais. Agora aquelas pessoas que não têm isso como valor vão simplesmente se tornar bacharéis sem essa consciência (Professor E - Informação verbal).

Ainda de acordo com o docente $\mathrm{E}$, muitas vezes a iniciativa de compreensão do tema parte dos próprios discentes, que trouxeram essa consciência de outros lugares. Ele afirma que "está incorporado nos valores individuais. Agora aquelas pessoas que não têm isso como valor vão simplesmente se tornar bacharéis em Administração sem essa consciência”. De acordo também com entrevistado $\mathrm{H}$, "os alunos refletem o conjunto de valores da nossa sociedade, e ela, a sociedade, não tem a sustentabilidade como um valor importante. Se assim o fosse, ao invés de carros e motos nas ruas, poderíamos ter transporte público de qualidade usando combustíveis alternativos [...]".

A metodologia e práticas de ensino adotadas pelos docentes não são a única forma de analisar a efetividade no ensino da temática de sustentabilidade, visto que os valores individuais e o interesse dos alunos em se envolver com estas questões podem impactar na aprendizagem em sala de aula, assim como nas pretensões futuras de atuação nessa área ao se inserirem no mercado de trabalho. Para os entrevistados, em sua maioria, a importância atribuída pelos discentes ao tema ocorre positivamente e é crescente, porém alguns salientam que ainda se concentra em uma minoria em sala de aula.

Alguns motivos que podem justificar o baixo interesse dos acadêmicos pelo tema foram levantados por seis entrevistados. São eles: a falta de conhecimento na área; a exaustão da abordagem superficial e conceitual do tema, sem aprofundamento e inovação e; os valores individuais, que influenciam na maneira como o ser humano lida com a sociedade e o meio ambiente. Os entrevistados A e E afirmam que muitas vezes há falta 
de conhecimento da temática por ela não ser muito abordada nas escolas, tanto no Ensino Fundamental quanto no Ensino Médio.

Ainda dentro do interesse dos alunos em aprofundar conhecimentos na área de sustentabilidade, o respondente J teceu uma crítica ao ensino atual da temática, afirmando que está ocorrendo de maneira exaustiva, o que posteriormente foi reafirmado por $\mathrm{G}$ ao dizer que "ainda é muito discurso, está virando uma terminologia muito senso comum, generalizada, e os próprios alunos estão cansados de todo mundo estar discutindo essa mesma questão". Ao utilizar esse ponto de vista como questionamento para outros docentes, o entrevistado I se posicionou da seguinte maneira:

Na realidade, eu acho que o que o meu colega quis dizer quando fala cansado é que o tema é abordado de forma superficial, muitas vezes, em sala de aula, não se aprofundando a temática. Todo mundo fala o que é sustentabilidade e o aluno não aguenta mais escutar a mesma coisa. Cada docente tem que trazer o tema de forma aplicada e aprofundada e, dando ferramentas, não passando conceitos sem aplicabilidade, senão fica só um ideal que todo professor acha bonito mencionar em sala de aula e essa não é a ideia de transversalidade do tema (Informação verbal).

$\mathrm{O}$ docente $\mathrm{K}$ concorda com essa afirmação dizendo que depende da forma como o tema é abordado e que por ser sempre atual "sempre surgem novos procedimentos e rotinas que têm a sustentabilidade como mote. Se você olha para o que é novidade, nunca vai ser chato, sempre vai ser interessante porque sempre vai ser novo né?!”.

Ao apresentar os temas extraídos dos melhores cursos de Administração do Brasil, foi possível perceber que todos têm conhecimento sobre os temas, sendo a "tomada de decisões" e as "discussões reflexivas" abordadas com grande ênfase pela maioria, recebendo notas entre 4 e 5. Já os temas "mercado verde" e "sustentabilidade, conceitos e aplicabilidade" foram os temas que mais receberam notas entre o e 2, o que revela pouca abordagem dentro das disciplinas ministradas pelos professores entrevistados.

O item "ética e moral" é trabalhado com frequência em sala de aula (notas $4 \mathrm{e}$ 5) por sete dos onze docentes, ao passo em que dois deles afirmam desconsidera-la em suas disciplinas. O mesmo cenário ocorre com o item 
"compromisso da empresa com a sociedade". Já os temas "Importância do meio ambiente e sua preservação"; "Consumo e seus efeitos"; "Leis e políticas públicas"; "Valores e atitudes"; "Processo de tomada de decisão" "Empreendedorismo e sustentabilidade" e; "Discussões reflexivas e que estimulam o senso crítico" são abordados por todos os docentes em suas aulas, com menos ou maior intensidade, o que evidencia o grau de importância destes conteúdos para a formação dos gestores. Todos os resultados obtidos nessa questão estão apresentados na Tabela 2.

Tabela 2 Frequência de abordagem dos temas durante as aulas

\begin{tabular}{|c|c|c|c|c|c|c|}
\hline \multirow[t]{2}{*}{ Tema } & \multicolumn{6}{|c|}{$\begin{array}{l}\text { Escala atribuída pelos docentes } \\
\text { Não relevante------Muito Relevante }\end{array}$} \\
\hline & 0 & 1 & 2 & 3 & 4 & 5 \\
\hline Ética e moral & 2 & 0 & 1 & 1 & 2 & 5 \\
\hline Compromisso da empresa com a sociedade & 2 & 1 & 0 & 1 & 3 & 4 \\
\hline Importância do meio ambiente e sua preservação & 0 & 3 & 2 & 2 & 3 & 1 \\
\hline Cultura, direitos e deveres & 1 & 1 & 2 & 2 & 3 & 2 \\
\hline Consumo e seus efeitos & 0 & 1 & 2 & 1 & 3 & 4 \\
\hline Sustentabilidade, conceitos, aplicabilidade & 2 & 4 & 1 & 2 & 1 & 1 \\
\hline Responsabilidade Social Corporativa & 1 & 2 & 2 & 3 & 3 & 0 \\
\hline Leis e políticas públicas & 0 & 2 & 2 & 3 & 3 & 1 \\
\hline Mercado Verde & 3 & 1 & 2 & 3 & 2 & 0 \\
\hline Tecnologia e Inovação & 1 & 0 & 0 & 1 & 4 & 5 \\
\hline Valores e atitudes & 0 & 1 & 3 & 1 & 3 & 3 \\
\hline Processo de tomada de decisão & 0 & 0 & 1 & 2 & 1 & 7 \\
\hline Empreendedorismo e sustentabilidade & 0 & 1 & 2 & 2 & 3 & 3 \\
\hline Imagem corporativa & 0 & 1 & 5 & 3 & 0 & 2 \\
\hline Discussões reflexivas que estimulam o senso crítico & 0 & 0 & 1 & 0 & 3 & 7 \\
\hline
\end{tabular}

Ainda na intenção de compreender apreciações dos professores em relação ao tema, colocou-se em pauta a discussão a respeito do ponto de vista deles fora da sala de aula, quanto ao objetivo ideal das práticas sustentáveis adotadas pelas organizações dentro de dois extremos: i) as práticas sustentáveis devem ser tratadas dentro das organizações visando efeitos na sociedade/ambiente e; ii) as práticas sustentáveis 
devem ser tratadas dentro das organizações visando efeitos na imagem e reputação da empresa.

As opiniões nesse quesito mais uma vez foram divididas, com seis docentes atribuindo maior importância aos fins sociais/ambientais, três considerando que as duas questões devem ser tratadas igualmente e apenas um considerando que o objetivo final deve focar na imagem/reputação. Uma das professoras alegou que esta pergunta é muito complexa para ser respondida, pois vai depender de cada organização, do tipo de negócio e setor onde está inserido. Para o entrevistado E, o melhor a fazer é unir o útil ao agradável, conciliando os dois objetivos. Já de acordo com o entrevistado D:

[...] a reputação é uma consequência, mas de forma alguma, como as organizações visam lucro, elas vão ter como objetivo apenas os impactos ambientais e sociais. A gente sabe que para as organizações o importante é ter lucro. Já tivemos grandes discussões sobre responsabilidade social. Um economista como Friedman falava "a empresa é responsável quando paga direitinho os trabalhadores e cumprem leis". Então, por mais que às vezes é colocado como se o grande objetivo fosse mitigar os impactos ambientais e sociais, o objetivo das organizações capitalista é sempre ter lucro. Então, essas duas coisas evidentemente vão ter que caminhar juntas. Eu acredito que dentro do prescritivo, do dever ser e não do ser, seria importante realmente que as organizações se preocupassem com impactos ambientais e sociais, e que a reputação viesse como consequência. E não fazer ações ambientais para ter reputação e é isso que elas fazem. O que eu vejo é uma inversão. Não vou ser bom para ir pro céu, vou ser bom por ser bom (Informação verbal).

Para finalizar as entrevistas, duas questões foram colocadas em pauta: a abordagem interdisciplinar/transversal do tema em sala de aula e as possíveis mudanças que poderiam ocorrer no curso a fim intensificar sua inserção. A importância da transversalidade foi defendida e ressaltada por quase todos os docentes, exceto por $\mathrm{E}$, que acredita que esta por si só não tem relevância, sendo apenas uma das formas de tratar o assunto. Para D, essa forma de abordagem é importante, porém não acontece na instituição, visto que "é cada um com sua disciplina, com pouca conversa. Pode-se dizer que o projeto conversa, mas as pessoas não se conversam". Fortalecendo 
ainda mais essa opinião, o docente $\mathrm{H}$ afirma que "[...] infelizmente a maioria dos professores encara suas disciplinas como "feudos" e não estão sensíveis à realização de interfaces. Isso acontece não só com o tema sustentabilidade, como também, com inovação e criatividade".

Por fim, a maior parte dos docentes entrevistados concordou que deve haver modificações no curso visando conscientizar os discentes da importância da temática sustentabilidade. Para D, não são necessárias grandes mudanças, sendo o aumento do diálogo entre os docentes a principal alteração necessária. Corroborando com essa expectativa, E afirma que as mudanças poderiam ocorrer:

[...] na sua estrutura, nos seus fundamentos filosóficos, [...] Então no âmbito básico, legal, está sendo cumprido, mas poderia ser muito mais, como por exemplo, na reformulação do próprio projeto pedagógico. Por exemplo, um projeto pedagógico que fosse multidisciplinar, em que as disciplinas conversassem mais. Hoje eu tenho a impressão que eu entro na sala, dou meu conteúdo, minha aula e pronto, como se fosse uma ilha isolada. Não interajo com outros professores, outros conteúdos. Não sei até que ponto aquilo está envolvendo as demais matérias. Essa responsabilidade cabe ao aluno, mas nem sempre o aluno tem essa percepção. Às vezes a ficha cai quando ele estiver lá no mercado de trabalho, e então ele perdeu a oportunidade de fazer esse link multidisciplinar. E uma das melhores formas de fazer esse link multidisciplinar é promover dentro da estrutura do projeto pedagógico um tipo de avaliação por meio de projetos de final de curso, voltados à Responsabilidade Social [...] Talvez se essa preocupação fosse uma preocupação macro da própria UFMS isso estaria de alguma forma sofrendo a influência da instituição.

Assim, dentre as mudanças sugeridas pelos docentes que visam à melhoria no ensino e na aprendizagem da temática de sustentabilidade, estão: a criação de disciplinas que tratem o tema de maneira específica e aprofundada; maior diálogo entre os professores e também com a coordenação do curso; mais reuniões pedagógicas para discussões sobre conteúdos e eventos; modificações no projeto pedagógico (estrutura e fundamentos); inserção da disciplina obrigatória de ética; maior interação entre as disciplinas e inserção de assuntos relacionados ao tema dentro das disciplinas já existentes. 


\section{CONSIDERAÇÕES FINAIS}

Temas relacionados à sustentabilidade vêm sendo incorporados em várias áreas e contam com a educação como aliada na conscientização e formação de cidadãos que levarão esses ensinamentos para vida pessoal e profissional. No que diz respeito à formação de futuros gestores, observa-se que por muito tempo a temática foi deixada de lado devido ao enfoque econômico dado pelos cursos superiores de Administração. Porém, hoje existe quase um consenso sobre a importância em formar administradores conscientes de seu papel na sociedade e preparados para lidar com questões econômicas, sociais e ambientais dentro das organizações, impactando direta ou indiretamente nas tomadas de decisões.

Com base na análise dos ementários dos dez melhores cursos de Administração do Brasil, foi possível verificar que ainda que seja formalmente trabalhado, em sua maioria, de maneira tímida e arbitrária (muitas vezes em disciplinas eletivas ou como tópico de alguma outra disciplina obrigatória), todas as instituições abordam algum aspecto relacionado ao tema. Essa constatação permite reafirmar o aumento da consciência sobre a importância da educação para promover mudanças deste teor e a necessidade que se criou em trata-lo dentro das especificidades de várias disciplinas.

Ao verificar que os melhores cursos de Administração do Brasil consideram a sustentabilidade e temas afins relevantes para a formação de gestores, optou-se por um estudo ainda mais específico e profundo sobre o funcionamento desses cursos e a forma como se dá a interação entre a teoria (ementa curricular) e a prática (conteúdo aplicado em sala de aula). Para isso, analisou-se o caso do curso de graduação em Administração da UFMS, campus de Campo Grande, permitindo conclusões confirmatórias e complementares, tais como o fato de que formalmente o assunto ainda é timidamente tratado dentro das disciplinas obrigatórias e é pauta de algumas disciplinas eletivas, o que mostra que apesar de haver um aumento de interesse pelo tema, a formação e atuação do profissional podem ser impactadas pelo fato dele ter, ou não, cursado tais disciplinas. 
Além disso, cabe aos docentes inserirem a temática dentro das disciplinas eletivas ou informalmente no planejamento das aulas das demais disciplinas. Tal autonomia na criação e manutenção da ementa curricular das disciplinas não obrigatórias traz pontos positivos, possibilitando a inserção de conteúdos atuais e considerados importantes pelos docentes, porém podem também gerar uma disparidade na formação dos administradores, visto que cada turma terá diferentes oportunidades de aprendizagem.

Outra conclusão do estudo foi a de que os docentes divergem sobre a relevância da temática, pois apesar de todos concordarem que é importante para a formação dos administradores, existem opiniões contrárias à sua abordagem, que é considerada insuficiente e exaustiva dentro do mesmo quadro de análise. É possível observar também que cada um tem um entendimento sobre o que é a sustentabilidade, o que abrange e como pode ser trabalhada, havendo enfoque por vezes nas questões sociais, ambientais ou econômicas.

Ainda que alguns docentes tenham certeza da importância de se trabalhar temas relacionados à sustentabilidade em suas aulas e formar gestores socialmente responsáveis, outros acreditam que um trato apenas conceitual seja suficiente, visto que o interesse pessoal de cada um, os valores individuais trazidos para sala de aula e as exigências do mercado vão modelar o profissional de acordo com o perfil requerido e as necessidades do momento.

Em estudo recente realizado por Gonçalves-Dias, Herrera e Cruz (2013) sugere que apesar do reconhecimento da importância das universidades para a promoção da sustentabilidade, estas ainda possuem currículos com objetivos distantes dos princípios almejados. Corroborando com essas ideias, Venzke e Nascimento (2013) afirmam haver necessidade de se trilhar caminhos que possibilitem a real inserção da sustentabilidade no ensino da Administração, visando até mesmo uma mudança epistemológica, que possibilite a libertação das amarras atuais, que engessam os conceitos relacionados à temática, e proporcionando uma abordagem mais complexa, que gere conhecimentos plurais.

Com base nas conclusões obtidas deste trabalho, é possível compreender que a temática da sustentabilidade é complexa e ainda pode ser muito 
explorada dentro dos cursos de Administração, tendo grande relevância na formação dos futuros gestores. Pode-se concluir que a UFMS não está alheia à inserção da temática dentro do curso de Administração, porém existem muitas possibilidades de melhoria e otimização desse processo, estando os docentes cientes disto. Sugere-se que pesquisas futuras busquem compreender a abordagem do tema em outras instituições, além de buscar compreender se há uma linha de comportamento padrão dos discentes da área de gestão em relação ao tema, no Brasil e no mundo, verificando possíveis influências de valores pessoais, assim como impactos de aspectos econômicos, sociais e culturais no comportamento do indivíduo. Para enriquecer os resultados, sugere-se que próximas pesquisas realizem análises que vão além dos documentos institucionais e das opiniões de docentes, como coleta de informações com coordenadores de curso, com empregadores e com os alunos, que são os principais afetados pela forma atual de ensino, buscando também a adoção de métodos de análise de dados qualitativos e quantitativos. 


\section{REFERENNCIAS}

AKTOUF, O. Ensino de Administração: por uma pedagogia para a mudança. Revista Organização \& Sociedade, v.12, n. 35, p. 151-159, 2005.

ARANHA, M.L.A. História da educação. 2.ed. São Paulo: Moderna, 1996.

BANERJEE, S. B. Who Sustains Whose Development? Sustainable Development and the Reinvention of Nature. Organization Studies, v. 24, n.1, p.143-180, 2003.

BARBIERI, J.C, SILVA, D. Educação Ambiental na formação do Administrador. São Paulo: Cengage Learning, 2011.

BAUER, M.W.; GASKELL, G. (Orgs.). Pesquisa qualitativa com texto, imagem e som: Um manual prático. Tradução por Pedrinho A. Guareschi. Petrópolis/RJ: Vozes, 2002.

BRASIL Lei no 6.938, de 31 de agosto de 1981. Dispõe sobre a Política Nacional do Meio Ambiente, seus fins e mecanismos de formulação e aplicação, e dá outras providências. Disponível em: <https://www.planalto.gov.br/ccivil_03/leis/16938.htm>. Acesso em: 26/08/2014.

BRASIL. Lei no 9.795, de 27 de abril de 1999. Dispõe sobre a educação ambiental, institui a Política Nacional de Educação Ambiental e dá outras providências. Diário Oficial da União, Brasília, DF, 28 abr.1999. Disponível em: <http://www.planalto.gov.br/ccivil_03/ leis/19795.htm>. Acesso em: 12/07/2014.

CAVALCANTI, C. (Org.). Desenvolvimento e Natureza: estudos para uma sociedade sustentável. São Paulo: Cortez, 2003.

COSTA, F.J. Valores pessoais e gestão socioambiental: um estudo com estudantes de administração. Revista de Administração Mackenzie, v. 14, n. 3 p. 183-208, 2013.

DECLARAÇÃO DA CONFERÊNCIA DAS NAÇÕES UNIDAS SOBRE O MEIO AMBIENTE HUMANO, 1972. Disponível em: <http://www.apambiente.pt/_zdata/Politicas/ DesenvolvimentoSustentavel/1972_Declaracao_Estocolmo.pdf $>$. Acesso em: 26/08/2014.

DEMAJOROVIC, J.; SILVA, H. C. O. Formação interdisciplinar e sustentabilidade em cursos de administração: desafios e perspectivas. Revista de Administração Mackenzie, v.13, n. 5, p. 39-64, 2012.

GHOSHAL, S. Bad management theories are destroying good management practices. Academy of Management Learning and Education, v. 4, n. 1, p. 75-91, 2005.

GONÇALVES-DIAS, S. L. F.; HERRERA, C. B.; CRUZ, M. T. de S. Desafios (e dilemas) para inserir "Sustentabilidade" nos currículos de administração: um estudo de caso. Revista de Administração Mackenzie, v.14, n.3, p. 119-153, 2013.

JACOBI, P.R. Educação Ambiental: o desafio da construção de um pensamento crítico, complexo e reflexivo. Educação e Pesquisa, v. 31, n. 2, p. 233-250, 2005. 
JACOBI, P.R.; RAUFFLET, E.; ARRUDA, M.P. Educação para a sustentabilidade nos cursos de administração: reflexão sobre paradigmas e práticas. Revista de Administração Mackenzie, v. 12, n. 3, p. 21-50, 2011.

LAMPERT, E. Educação para a cidadania. Porto Alegre: Sulina, 1999.

MADEIRA, A.C.F.D. Indicadores de sustentabilidade para instituições de Ensino Superior. Faculdade de Engenharia da Universidade do Porto. Porto, 2008.

MANITOBA EDUCATION AND TRAINING, Education for a sustainable future: a resource for curriculum developers, teachers, and administrators, 2000. Disponível em:

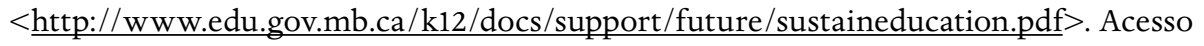
em 25/08/2014.

MEBRATU, D. Sustainability and sustainable development: historical and conceptual review, International Institute for Industrial Environmental Economics, Lund University, 1998.

MINISTÉRIO DO MEIO AMBIENTE-A. Carta de Belgrado. Disponível em: <http:// www.mma.gov.br/port/sdi/ea/deds/pdfs/crt_belgrado.pdf> . Acesso em: 24/08/2014.

MINISTÉRIO DO MEIO AMBIENTE-B. Agenda 21 Global. Disponível em:

$<\underline{\text { http://www.mma.gov.br/responsabilidade-socioambiental/agenda-21/agenda-21- }}$ global>. Acesso em: 24/08/2014.

MINISTÉRIO DO MEIO AMBIENTE-C. Declaração de Thessaloniki. Disponível em: $<$ http://www.mma.gov.br/educacao-ambiental/item/8070-declara\%C3\%A7\%C3\%A3ode-thessaloniki>. Acesso em: 24/08/2014.

OLIVEIRA, F.B.; SANT’ANNA A.S.; DINIZ, D.M. Contribuição dos cursos de graduação em Administração: desenvolvimento de lideranças socialmente responsáveis? Revista Economia \& Gestão, v. 14, n. 34, p. 137-167, 2014.

PALMA, L. C.; OLIVEIRA, L. M. de; VIACAVA, K. R. Sustainability in Brazilian federal universities. International Journal of Sustainability in Higher Education, v. 12, n. 3, p. $250-258,2011$.

PORTER, M.E.; KRAMER, M.R. Strategy and Society: the link between competitive advantage and corporate social responsibility. Harvard Business Review, v. 84, n. 2, p. 76-82, 2006.

RANKING UNIVERSITÁRIO FOLHA 2014. Disponível em: < http://ruf.folha.uol.com. br/2014>. Acesso em: 30/01/2015.

REDCLIFT, M. Sustainable development: Exploring the contradictions. London: Methuen, 1987.

RICHARDSON, R. J.; PERES, J. A. S. DE.; WANDERLEY, J. C. V.; CORREIA, L. M.; PERES, M. H. M. Pesquisa social: métodos e técnicas. 3.ed. São Paulo: Atlas, 1999.

RUSCHEINSKY, A. (Org.). Educação Ambiental: Abordagens múltiplas. Porto Alegre: Artmed, 2002. 
SILVA, H. H. M. CAMPANARIO, M. A. SOUZA. M. T. S. O isomorfismo na educação ambiental como tema transversal em programas de graduação em administração. Revista de Ciências da Administração, v. 15, n. 37, p.170-186, 2013.

SILVA, M.E.; CZYKIEL, R.; FIGUEIRÓ, P.S.; SANTOS, W. S. F.; GALVÃO, U. P. Um espelho, um reflexo! A Educação para a Sustentabilidade como subsídio para uma tomada de decisão consciente do administrador. Revista de Administração Mackenzie, v. 14, n. 3, p. 154-182, 2013.

SINAY, M.C.F.; DALBEM, M.C.; LOUREIRO, I.A.; VIEIRA, J. M. Ensino e pesquisa em gestão ambiental nos programas brasileiros de pós-graduação em administração. Revista de Administração Mackenzie, v. 14, n. 3, p. 55-82, 2013.

TEODÓSIO, A. S. S.; FORTES, F. Z.; BARBIERI, J. C.; GONÇALVES-DIAS, S. L. F. Muito barulho por nada? A difusão de temas ambientais nos cursos de graduação em administração no Brasil. In: ENCONTRO NACIONAL DE GESTÃO EMPRESARIAL E MEIO AMBIENTE (Engema), 8., 2005. Rio de Janeiro. Anais... Rio de Janeiro: FEA/ USP, FGV/EAESP, v. 1. p. 263-263, 2005.

UNESCO. Década da Educação das Nações Unidas para um Desenvolvimento Sustentável, 2005-2014: documento final do esquema internacional de implantação. Brasília:

UNESCO, 2005.

VASCONCELOS, K. C. A.; SILVA JUNIOR, A. S.; SILVA, P. O. M. Educação gerencial para atuação em ambientes de negócios sustentáveis: desafios e tendências de uma escola de negócios brasileira. Revista de Administração Mackenzie, v. 14, n. 4, p. 45-75, 2013.

VENZKE, C.S.; NASCIMENTO, L.F.M. Caminhos e desafios para a inserção da sustentabilidade socioambiental na formação do administrador brasileiro, Revista de Administração Mackenzie, v. 14, n. 3, p. 26-54, 2013.

VERGARA, S.C. Projetos e relatórios de pesquisa em Administração. 13.ed. São Paulo: Atlas, 2011.

WORLD COMMISSION ON ENVIRONMENT AND DEVELOPMENT (WCED), 1987. Our Common Future. Oxford University Press, Oxford. Disponível em: $<$ http://conspect. nl/pdf/Our Common Future-Brundtland Report 1987.pdf $>$. Acesso em: 26/08/2014. 


\section{DADOS DOS AUTORES}

\section{IZABELA TEIXEIRA FRANCO* izaa.franco@hotmail.com} Mestre em Administração pela Universidade Federal de Mato Grosso do Sul Instituição de vinculação: Universidade Federal de Mato Grosso do Sul Campo Grande/MS - Brasil

Áreas de interesse em pesquisa: Responsabilidade Social Empresarial.

${ }^{\star}$ Av. Senador Filinto Müller, 1555, Unidade 10-A Cidade Universitária Campo Grande/MS 79070-900

\section{MAÍSA GOMIDE TEIXEIRA 85maisatx@gmail.com}

Doutora em Administração pela Universidade Federal do Paraná Instituição de vinculação: Universidade Federal de Mato Grosso do Sul Campo Grande/MS - Brasil

Áreas de interesse em pesquisa: Estudos organizacionais, teoria institucional, processo decisório e gestão sustentável.

DENISE BARROS DE AZEVEDO denise.azevedo@ufms.br Doutor em Agronegócio pela Universidade Federal do Rio Grande do Sul Instituição de vinculação: Universidade Federal de Mato Grosso do Sul Campo Grande/MS - Brasil

Áreas de interesse em pesquisa: Sustentabilidade em Agronegócios.

ROSAMARIA COX MOURA-LEITE rosamaria.leite@ufms.br Doutora em Administração pela Universidad de Salamanca - Espanha Instituição de vinculação: Universidade Federal de Mato Grosso do Sul Campo Grande/MS - Brasil

Áreas de interesse em pesquisa: Ensino e Pesquisa em Administração e Responsabilidade Social Empresarial. 